\title{
Rat Aortic Endothelial Cell Motility Dependence on Flow Rate
}

\author{
Paula J. Bernal, Jenny M. Karlsson, Simon C. Watkins, Catherine J. Baty \\ Center for Biological Imaging, Department of Cell Biology and Physiology, University of \\ Pittsburgh, 3500 Terrace St. BST S220.5, Pittsburgh, PA 15217
}

The behavior of migrating eukaryotic cells using live cell imaging has become of great importance in numerous fields. Several studies have shown that cell dissociation, seeding density, time of cultivation and substrate concentration have a significant effect on cell speed [1]. An important parameter to consider is the effect of different flow rates, and their related shear stress on the average cell motility. The aim of this study is to determine the effect of different flow rates on the motility of live rat aortic endothelial cells for long-term experiments in a closed chamber system.

Rat aortic endothelial cells (RAECs) were grown on $40 \mathrm{~mm}^{2}$ gelatin $(0.02 \%)$ coated coverslips at $37^{\circ} \mathrm{C}$ and $5 \% \mathrm{CO}_{2}$, in MDCB-131 media with FBS (10\%) and antibiotics (VEC Technologies Inc, Resselaer, NY) until confluent. Prior to imaging, a diametric scratch was made exposing a cell-free region approximately 25 to $30 \mu \mathrm{m}$ wide. The coverslips were mounted in a closed chamber system (FCS2 ${ }^{\circledR}$, Bioptechs, Inc, Butler, PA), aligning the scratch longitudinally with the media flow. The chamber was additionally equipped with a grid designating 6 regions along the scratch, each approximately $0.32 \mathrm{~cm}$ long, attached to the outside the chamber's self-locking base. The coverslips were exposed to media with standard gas concentration at different media flow rates ranging from $0.5 \mathrm{ml} / \mathrm{h}$ to $10 \mathrm{ml} / \mathrm{h}$ (KDS 100 syringe pump, KD Scientific, Holliston, MA). Differential interference contrast (DIC) images were taken every $20 \mathrm{~min}$ at 12 different positions with either a Nikon Eclipse TE300 or Olympus IX70, with 20X objectives. Cellular motility was analyzed with MetaMorph (Universal Imaging Corp. Downingtown, PA), and was measured as the average speed of the cells' nucleus along their migratory pathway for at least 7 hours (Figure 1). Regional and total average speeds were determined. Average cell motility was compared among regions and among media flow rates. Statistical analyses were performed by one-way ANOVA followed by Tukey's HSD post-hoc test to determine specific differences between groups with a significance level of $p<0.05$.

Previously we observed differences in gap closure along the scratch which seemed to correspond to the cells distance from the media inflow, so regional motility was investigated. Cellular average speed was measured for 20 cells per region. The regional motility analysis revealed no significant difference between positions regardless of flow rate. A representative graph is shown in Figure $2 \mathrm{~A}$. Different flow rates resulted in alterations in the average cell motility, with higher motility rates for lower media flow rates (Figure 2B). Statistical differences were found for any pair of flow rates, except among flow rates above $2.5 \mathrm{ml} / \mathrm{h}$. Previous studies on bovine and human umbilical aortic endothelial cells showed increased motility with increased shear stress under slightly different settings [2,3]. The decreased motility at high flow rates found in our study, could be derived from the additional energy expenditure related with the activation of specific sensors and ion channels by shear stress [2], resulting in cytoskeletal reorganization. Additionally, high flow rates could exert such high cortical tension, especially when applied perpendicular to the cells movement, altering the normal cytoskeleton renewal and traffic [4]. Future studies will be needed to determine if the same relationship can be found when the media flows parallel to the wound healing direction. 


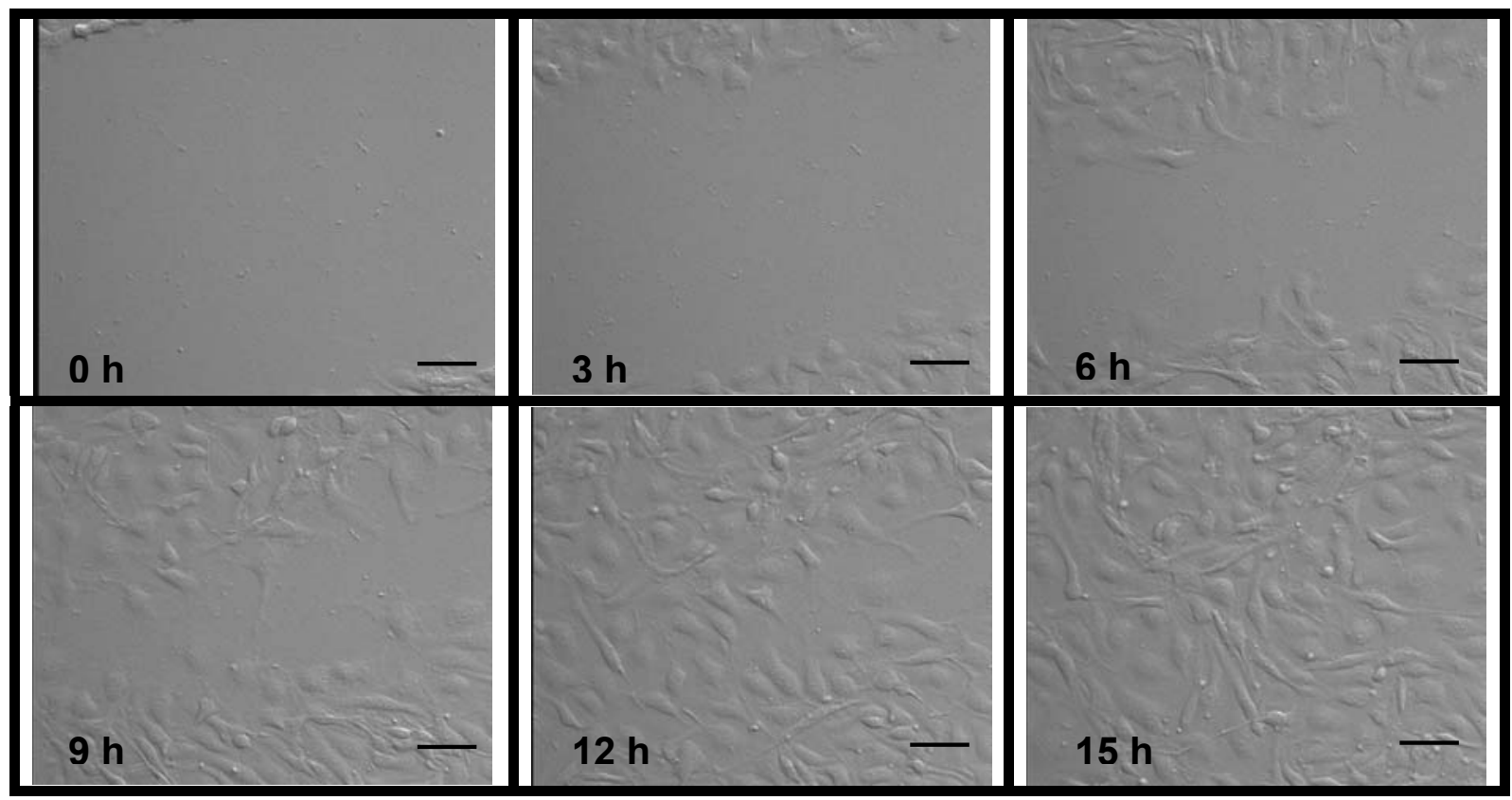

Figure 1. RAEC migration process. Photographs show cell migration progression along the scratch with a media flow of $0.5 \mathrm{ml} / \mathrm{h}$ (time shown on left corner). Scale bars $=50 \mu \mathrm{m}$.

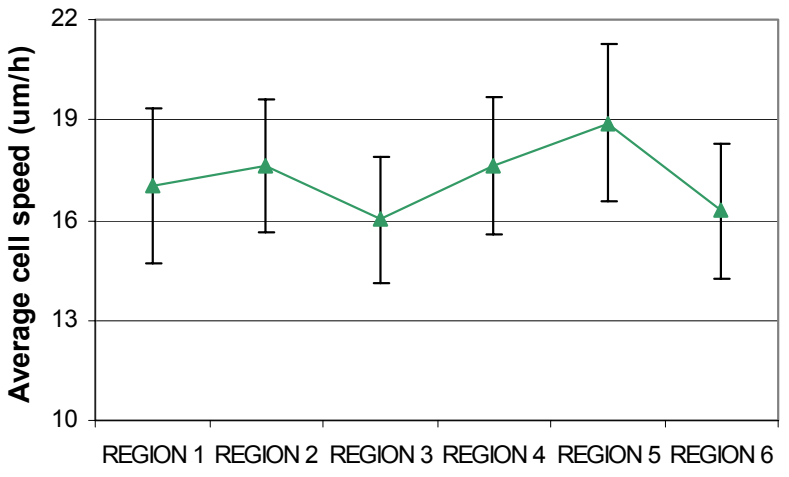

A

Out-flow

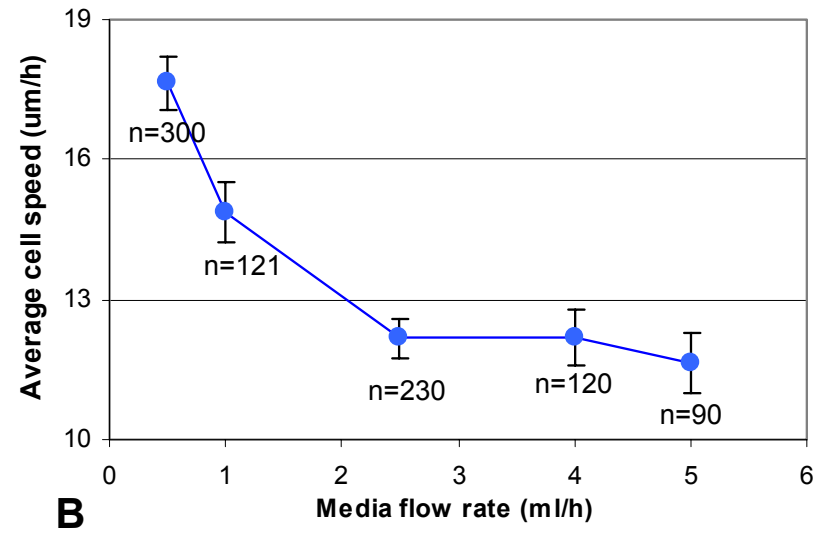

Figure 2. Average cell motility. Average cell speed is shown over the different regions at a constant flow rate (A) and total experimental average at different media flow rates (B). Error bars determine the 95\% confidence interval for each of the groups.

\section{References:}

[1] R. Hartmann-Petersen, et al. Cytometry 40 (2000) 260-270.

[2] A. Gojova and A. I. Barakat. J Appl Physiol (2005) article in press.

[3] M. L. Albuquerque et al. Am J Physiol Heart Circ Physiol 279 (2000) H293-302.

[4] G. Albrecht-Buehler. Cell Motil. Cytoskeleton 7 (1987): 54-67. 